\title{
The $\beta$-actin mRNA zipcode regulates epithelial adherens junction assembly but not maintenance
}

\author{
NATASHA GUTIERREZ, ${ }^{1}$ ITUA EROMOBOR, ${ }^{1}$ RYAN J. PETRIE, ${ }^{2}$ PAVAN VEDULA, ${ }^{1}$ LISSETTE CRUZ, ${ }^{1}$ \\ and ALEXIS J. RODRIGUEZ ${ }^{1,3}$ \\ ${ }^{1}$ Department of Biological Sciences, Rutgers University Newark, Newark, New Jersey 07102, USA \\ ${ }^{2}$ National Institutes of Health, National Institute of Dental and Craniofacial Research, Bethesda, Maryland 20892, USA
}

\begin{abstract}
Epithelial cell-cell contact stimulates actin cytoskeleton remodeling to down-regulate branched filament polymerization-driven lamellar protrusion and subsequently to assemble linear actin filaments required for E-cadherin anchoring during adherens junction complex assembly. In this manuscript, we demonstrate that de novo protein synthesis, the $\beta$-actin $3^{\prime}$ UTR, and the $\beta$ actin mRNA zipcode are required for epithelial adherens junction complex assembly but not maintenance. Specifically, we demonstrate that perturbing cell-cell contact-localized $\beta$-actin monomer synthesis causes epithelial adherens junction assembly defects. Consequently, inhibiting $\beta$-actin mRNA zipcode/ZBP1 interactions with $\beta$-actin mRNA zipcode antisense oligonucleotides, to intentionally delocalize $\beta$-actin monomer synthesis, is sufficient to perturb adherens junction assembly following epithelial cell-cell contact. Additionally, we demonstrate active RhoA, the signal required to drive zipcode-mediated $\beta$-actin mRNA targeting, is localized at epithelial cell-cell contact sites in a $\beta$-actin mRNA zipcode-dependent manner. Moreover, chemically inhibiting Src kinase activity prevents the local stimulation of $\beta$-actin monomer synthesis at cell-cell contact sites while inhibiting epithelial adherens junction assembly. Together, these data demonstrate that epithelial cell-cell contact stimulates $\beta$-actin mRNA zipcode-mediated monomer synthesis to spatially regulate actin filament remodeling, thereby controlling adherens junction assembly to modulate cell and tissue adhesion.
\end{abstract}

Keywords: RhoA and Src signaling; actin cytoskeleton regulation; actin mRNA zipcodes; adherens junction assembly; translation regulation

\section{INTRODUCTION}

Epithelial cell-cell adhesion is important in multicellular organisms for normal tissue homeostasis during adulthood and to establish tissue boundaries during embryonic development. Throughout an organism's life, its epithelial tissues balance dynamic cell rearrangement with barrier maintenance. Epithelial adherens junction complex assembly/disassembly dynamically modulates cell-cell adhesion by regulating the recruitment and anchoring of multiprotein cadherin/catenin adhesion complexes to contact localized actin filaments. In fact, epithelial cell-cell contact simulates numerous signal transduction pathways to coordinate cadherin/catenin complex assembly and anchoring to actin filaments, leading to adherens junction assembly and cell adhesion (Braga et al. 1997; McLachlan et al. 2007; Yamada and Nelson 2007; Harris and Tepass 2010).

Epithelial adherens junction assembly occurs in three stages: contact initiation, contact expansion, and junction matu-

\footnotetext{
${ }^{3}$ Corresponding author

E-mail ajrod@andromeda.rutgers.edu

Article published online ahead of print. Article and publication date are at http://www.rnajournal.org/cgi/doi/10.1261/rna.043208.113.
}

ration. During all the stages of adherens junction assembly, cadherin/catenin complexes accumulate in close proximity to actin cytoskeleton remodeling sites. For example, E-cadherin directly regulates actin filament polymerization during the contact initiation stage of epithelial adherens junction assembly by binding and localizing Arp2/3 complexes to cellcell contact sites (Kovacs et al. 2002b). Also during the contact initiation stage of adherens junction assembly, post-translationally arginylated- $\beta$-actin monomers polymerize into branched filament arrays driving lamellar protrusion in areas with high concentrations of activated Arp2/3 complexes (Kovacs et al. 2002a; Karakozova et al. 2006; Saha et al. 2010). Thereafter, E-cadherin homophilic interactions stimulate accumulation of other actin-binding proteins including formin, mDia, and Ena/Vasp to the contact zone, where they stimulate linear filament polymerization to drive contact expansion (Sahai and Marshall 2002; Kobielak et al. 2004;

\footnotetext{
(C) 2014 Gutierrez et al. This article is distributed exclusively by the RNA Society for the first 12 months after the full-issue publication date (see http://rnajournal.cshlp.org/site/misc/terms.xhtml). After 12 months, it is available under a Creative Commons License (Attribution-NonCommercial 4.0 International), as described at http://creativecommons.org/licenses/bync/4.0/.
} 
Scott et al. 2006; Carramusa et al. 2007). Thus, E-cadherin adherens junction complexes direct actin cytoskeleton remodeling by coordinating actin-binding protein accumulation at cell-cell contact sites. Moreover, during the contact expansion stage of adherens junction assembly, E-cadherin/ a-catenin adherens junction complex anchoring to the newly remodeled actin cytoskeleton increases $\alpha$-catenin levels locally, inactivating Arp2/3 complex activity and consequently branched actin filament polymerization. Therefore, in addition to their "traditional" role in cell adhesion, adherens junction complex proteins at cell-cell contact sites also stimulate branched filament disassembly to inhibit lamellar protrusion and establish favorable conditions for contact expansion (Drees et al. 2005).

Dynamic actin filament remodeling, therefore, regulates the transition from contact initiation to contact expansion. Consequently, actin filament polymerization inhibitors perturb cell-cell adhesion (Jaffe et al. 1990; Angres et al. 1996). In fact, directed actin filament polymerization is a well-established force driving epithelial cell-cell adhesion (Vasioukhin et al. 2000). During the contact expansion stage of epithelial adherens junction assembly, linear actin filaments, E-cadherin, and $\beta$-catenin colocalize at cell-cell contact sites in numerous cell types (Gloushankova et al. 1997; Zhang et al. 2005; Rodriguez et al. 2006; Cavey et al. 2008). Importantly, actin filament polymerization is spatially regulated by controlling the location of $\beta$-actin monomer synthesis (Shestakova et al. 2001; Rodriguez et al. 2006, 2008; Yao et al. 2006).

A 28-nt sequence in the $3^{\prime}$ untranslated region (UTR) of $\beta$ actin mRNA, called the zipcode, is the cis element used to spatially regulate $\beta$-actin monomer synthesis (Rodriguez et al. 2006, 2008). The trans factor, Zipcode Binding Protein-1 (ZBP1), binds this zipcode sequence to inhibit mRNA translation during transport through the cytoplasm (Huttelmaier et al. 2005). Active RhoA is the signal required to localize the translationally repressed $\beta$-actin mRNA to the cell periphery (Latham et al. 2001). Subsequently, $\beta$-actin monomer synthesis is initiated at the appropriate cytoplasmic location by relieving translation inhibition via Src-mediated phosphorylation of ZBP1 (Huttelmaier et al. 2005). As a result, adherens junction assembly in $\mathrm{N}$-cadherin expressing myoblast cells is impaired when $\beta$-actin monomer synthesis is delocalized by $\beta$-actin mRNA zipcode deletion (Rodriguez et al. 2006). These data demonstrate that cell-cell contact initiates $3^{\prime}$ UTR-dependent $\beta$-actin monomer synthesis to stimulate cadherin accumulation and anchoring at cell-cell contact sites. However, the specific role of the $\beta$-actin mRNA zipcode following epithelial cell-cell contact has yet to be investigated.

In this report, we demonstrate that de novo protein synthesis, the $\beta$-actin $3^{\prime}$ UTR, and the $\beta$-actin mRNA zipcode are all required for epithelial adherens junction assembly but not maintenance. Mechanistically, we demonstrate that the $\beta$-actin $3^{\prime}$ UTR and, more specifically, the $\beta$-actin mRNA zipcode sequence regulate the spatial distribution of $\beta$-actin monomer synthesis to locally increase $\beta$-actin monomer levels, thereby stimulating filament polymerization and adherens junction complex assembly at epithelial cell-cell contact sites. Additionally, we demonstrate that the localization of the active RhoA signal, required for zipcode mRNA targeting to cellcell contact sites, itself requires expression of $\beta$-actin mRNA with a functional zipcode sequence. Moreover, we demonstrate active Src, whose kinase activity is required to relieve ZBP1-mediated translation inhibition, is required to stimulate epithelial cell-cell contact site-localized $\beta$-actin monomer synthesis and adherens junction assembly. These results establish a key role for the $\beta$-actin mRNA zipcode in spatially regulating $\beta$-actin monomer synthesis, to organize localized actin filament polymerization and control epithelial adherens junction assembly.

\section{RESULTS}

\section{The $\beta$-actin mRNA 3' UTR is required for epithelial adherens junction complex assembly}

Previously, we demonstrated that deleting the $\beta$-actin mRNA $3^{\prime}$ UTR in a TC-GFP- $\beta$-actin reporter delocalizes $\beta$-actin monomer synthesis and perturbs myoblast adherens junction complex assembly (Rodriguez et al. 2006). To investigate the extent to which the $\beta$-actin mRNA $3^{\prime}$ UTR is required for epithelial adherens junction assembly, we generated stable MDCK cell lines expressing TC-GFP- $\beta$-actin with or without the $\beta$-actin $3^{\prime}$ UTR and investigated junction assembly using the $\mathrm{Ca}^{2+}$ switch method (Fig. 1). At steady state, MDCK cells expressing full-length TC-GFP- $\beta$-actin assemble a confluent monolayer with strong E-cadherin/F-actin/ $\beta$-actin colocalization observed at cell-cell contact sites (Fig. 1A, FL SS). After $1 \mathrm{~h}$ in low calcium media, this confluent monolayer disassembles, characterized by reduced E-cadherin/F-actin/ $\beta$-actin colocalization at the cell periphery (Fig. 1A, FL LC). After switching to $\mathrm{Ca}^{2+}$-containing recovery media for 180 min, this confluent monolayer reassembles, characterized by TC-GFP- $\beta$-actin colocalization with a subset of phalloidin-stained cell-cell contact-localized actin filaments $3 \mathrm{~h}$ post-contact (Fig. 1A, FL Rec 180, cf. F-actin and $\beta$-actin). Additionally, E-cadherin also colocalizes with TC-GFP- $\beta$-actin and, consequently, with a subset of phalloidin-stained actin filaments at cell-cell contact sites $3 \mathrm{~h}$ post-contact (Fig. 1A, Rec 180 , cf. E-cadherin to $\beta$-actin and F-actin). In contrast, at steady state, MDCK cells expressing $3^{\prime}$ UTR-deleted TC-GFP$\beta$-actin are unable to assemble a confluent monolayer with Ecadherin and TC-GFP- $\beta$-actin exhibiting low levels of cell-cell contact site colocalization (Fig. 1A, $\Delta 3^{\prime}$ UTR SS). After $1 \mathrm{~h}$ in low calcium media, the $\Delta 3^{\prime}$ UTR $\beta$-actin MDCK cells remain nonadherent and exhibit a rounded phenotype (Fig. 1A, $\Delta 3^{\prime}$ UTR LC). After switching to $\mathrm{Ca}^{2+}$ recovery media for 180 min, MDCK cells expressing $\Delta 3^{\prime}$ UTR TC-GFP- $\beta$-actin were unable to assemble a confluent monolayer and exhibit low levels of cell-cell contact-localized $\beta$-actin/E-cadherin colocalization (Fig. 1A, $\Delta 3^{\prime}$ UTR Rec 180 , cf. $\beta$-actin and F-actin). 


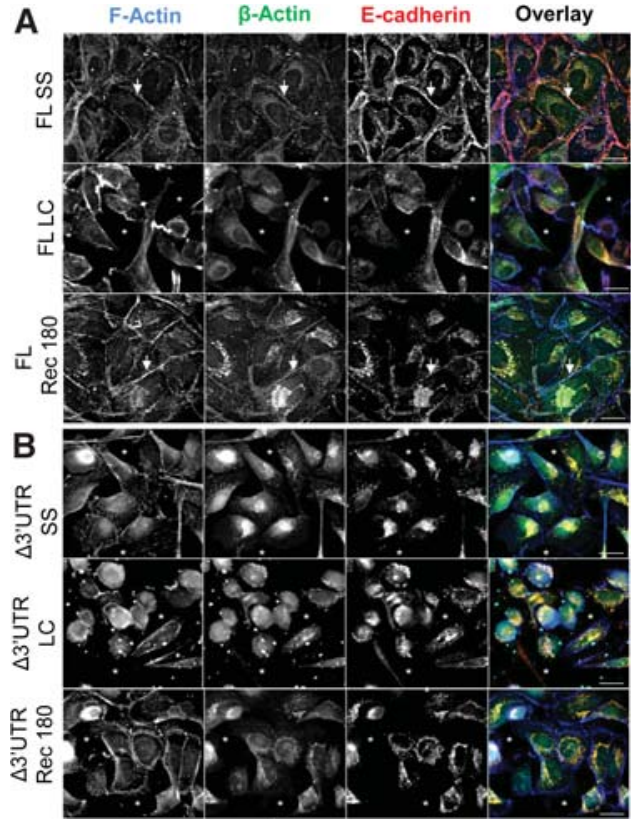

FIGURE 1. $\beta$-actin monomers incorporate into filaments at cell contacts in MDCK cells in a $3^{\prime}$ UTR-dependent manner. (A) De-convolved single plane epifluorescence image of MDCK cells expressing full-length $\beta$-actin GFP (green) at steady state (SS), in $1 \mathrm{~h} \mathrm{low} \mathrm{Ca}^{2+}$ (LC), or $3 \mathrm{~h}$ post- $\mathrm{Ca}^{2+}$ switch experiment (Rec 180). F-actin was stained by Alexa350 (blue) and E-cadherin using Cy3 (red). (B) De-convolved single plane epifluorescence image of MDCK cells expressing $\Delta 3^{\prime}$ UTR $\beta$ actin (green) at steady state (SS), in $1 \mathrm{~h} \mathrm{low} \mathrm{Ca}^{2+}$ (LC), or $3 \mathrm{~h}$ post-Ca ${ }^{2+}$ switch experiment (Rec 180). F-actin was stained by Alexa350 (blue) and E-cadherin using Cy3 (red). Arrows indicate the places where puncta of $\beta$-actin GFP are incorporated into filaments along the contact. Note asterisks, which indicate holes in the monolayer. Scale bars, $20 \mu \mathrm{m}$.

As a consequence, in $3^{\prime}$ UTR-deleted TC-GFP- $\beta$-actin-expressing MDCK cells, E-cadherin does not colocalize with cell-cell contact-localized actin filaments, reducing its accumulation at the contact zone $3 \mathrm{~h}$ post-contact (Fig. 1A, cf. $\mathrm{E}$-cadherin to $\beta$-actin and F-actin). These data demonstrate that the $\beta$-actin $3^{\prime}$ UTR is required for E-cadherin/F-actin cell-cell contact site colocalization and, consequently, epithelial adherens junction assembly $3 \mathrm{~h}$ post-contact.

\section{New protein synthesis is required for epithelial adherens junction complex assembly but not maintenance}

Since the $\beta$-actin mRNA 3' UTR controls the spatial distribution of $\beta$-actin monomer synthesis through mRNA zipcode/ zipcode binding protein 1 (ZBP1)-regulated mRNA translation, we investigated the extent to which de novo protein synthesis is required for epithelial adherens junction assembly using the $\mathrm{Ca}^{2+}$ switch method. MDCK cells expressing full-length TC-GFP- $\beta$-actin were $\mathrm{Ca}^{2+}$-switched, and adherens junction assembly was assessed by quantifying colocalization between immunofluorescence-labeled E-cadherin and phalloidin-labeled actin filaments (Fig. 2A). At steady state, E-cadherin and F-actin exhibit strong colocalization at cell-cell contact sites (Fig. 2A, SS, cf. E-cadherin and F-actin). After $1 \mathrm{~h}$ in low $\mathrm{Ca}^{2+}$ media, E-cadherin and F-actin colocalization is significantly reduced, and the cellular monolayer is disrupted (Fig. 2A, LC). After $180 \mathrm{~min}$ in $\mathrm{Ca}^{2+}$ recovery media with the global translation inhibitor cycloheximide, E-cadherin and F-actin fail to reestablish strong colocalization at cell-cell contacts sites, and the organization of the monolayer remains perturbed (Fig. 2A, Rec180+Inh). In contrast, after $180 \mathrm{~min}$ in $\mathrm{Ca}^{2+}$ recovery media without inhibiting translation, E-cadherin and F-actin begin to reestablish strong colocalization at cell-cell contact sites as the organization of the monolayer is restored (Fig. 2A, Rec180-Inh). Significantly, inhibiting translation with cycloheximide in steady-state MDCK monolayers for $3 \mathrm{~h}$, without first disassembling the adherens junction complexes with low $\mathrm{Ca}^{2+}$, does not significantly reduce E-cadherin/F-actin colocalization at cell-cell contact sites or perturb monolayer integrity (Fig. 2A, SS + Inh). To quantify the extent of adherens junction assembly/disassembly, we derived a mathematical measure of Ecadherin/F-actin colocalization called the asymmetry coefficient. The asymmetry coefficient is the ratio of the Pearson's correlation of colocalization for E-cadherin and F-actin fluorescence staining at cell-cell contact sites divided by their cytoplasmic Pearson's correlations (Supplemental Fig. 1). Consequently, to assess adherens junction assembly during $\mathrm{Ca}^{2+}$ switch experiments, we divided the steady-state asymmetry coefficient by the asymmetry coefficient $3 \mathrm{~h}$ post-contact and multiply by 100 to derive the adherens junction complex percent recovery (Fig. 2B,C; Supplemental Fig. 1). As shown in Figure 2B, E-cadherin and F-actin strongly colocalize at cell contact sites $(\mathrm{AC}>1)$ during steady state, but this contact-localized colocalization is lost following $1 \mathrm{~h}$ in low $\mathrm{Ca}^{2+}$ media or $3 \mathrm{~h}$ post-contact $(\mathrm{AC}<1)$ when cells are incubated in $\mathrm{Ca}^{2+}$ recovery media containing translation inhibitors (Fig. 2B, cf. SS, LC, and Rec+Inh). In contrast, in epithelial cells treated with $\mathrm{Ca}^{2+}$ recovery media without translation inhibitors, E-cadherin/F-actin colocalization recovers to near steady-state levels (AC $>1) 3 \mathrm{~h}$ post-contact (Fig. 2B, Rec-Inh). Importantly, inhibiting global translation with cycloheximide or puromycin for $3 \mathrm{~h}$ in steadystate epithelial monolayers had no significant effect on Ecadherin/F-actin colocalization (AC > 1), demonstrating that de novo protein synthesis is not required to maintain preexisting epithelial adherens junctions (Fig. 2C). These data are summarized in Figure 2D, where the addition of translation inhibitors during $\mathrm{Ca}^{2+}$ recovery is shown to significantly inhibit adherens junction assembly, but their addition to steady-state epithelial monolayers has no significant effect on the integrity of preexisting adherens junction complexes (Fig. 2D). Incredibly, even though these data demonstrate a vital role for new protein synthesis during epithelial adherens junction assembly, Western blots with antibodies against the adherens junction proteins, E-cadherin, $\beta$-catenin, and $\beta$-actin demonstrate no significant difference in their total 

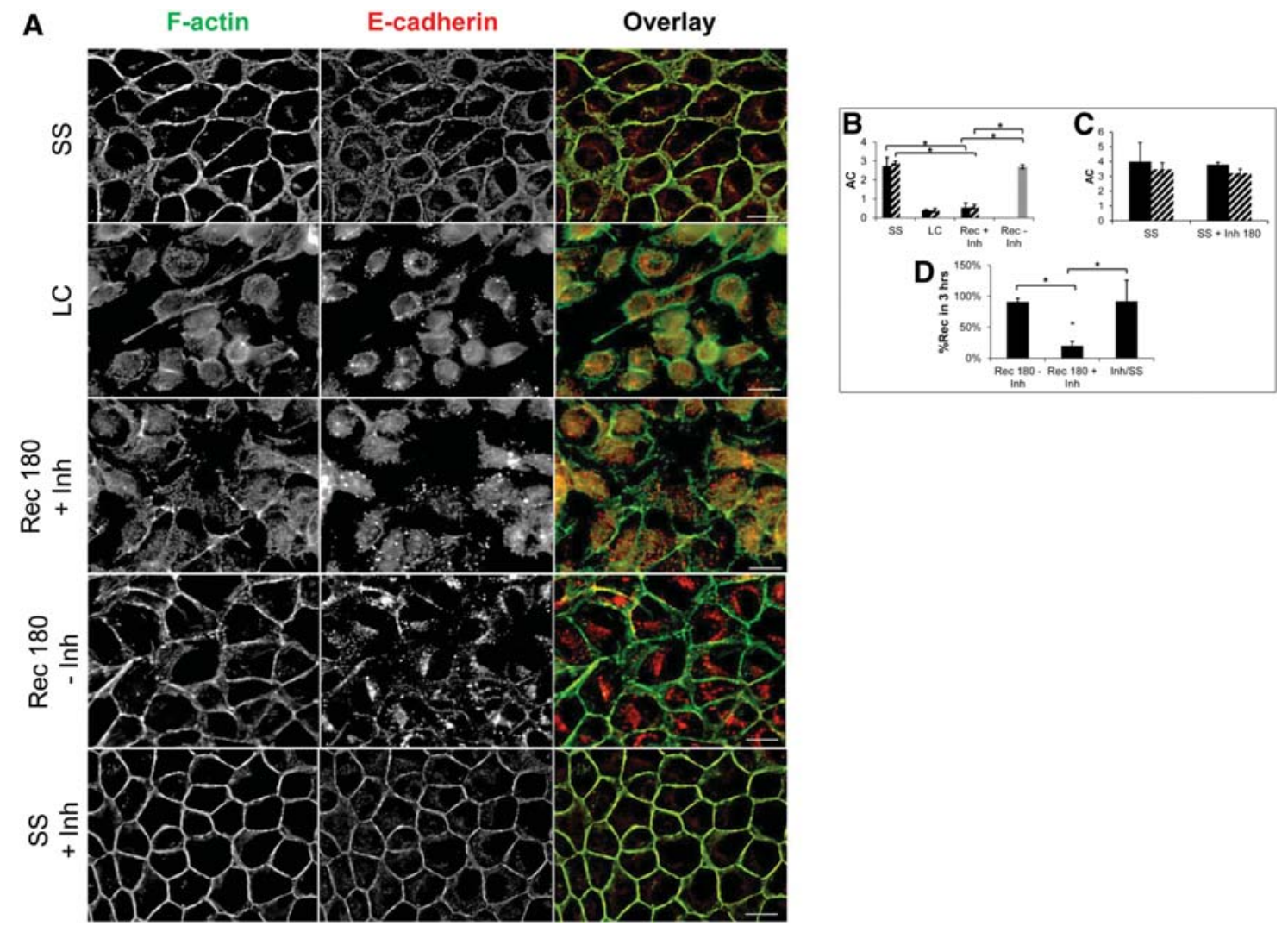

FIGURE 2. De novo protein synthesis is required to assemble but not maintain epithelial AJ complexes. (A) De-convolved epifluorescence images of a single plane of MDCK cells at steady state (SS), cells treated with low $\mathrm{Ca}^{2+}$ media for $1 \mathrm{~h}$ (LC), or cells after $3 \mathrm{~h}$ in Ca ${ }^{2+}$-containing recovery media without (Rec 180-Inh) or with (Rec 180-Inh) cycloheximide during $\mathrm{Ca}^{2+}$ switch experiments. F-actin (green) is stained with Alexa488-phalloidin, and E-cadherin is stained by immunofluorescence (red), with numerous AJ complexes (yellow) observed at cell contact sites. Cycloheximide was also applied to monolayers at steady state (SS + Inh) for $3 \mathrm{~h}$. (Boxed panel) Graphs represent the asymmetry coefficient (AC) and percent recovery (\% Rec) during MDCK $\mathrm{Ca}^{2+}$ switch experiments. (B) $\mathrm{AC}$ during $\mathrm{Ca}^{2+}$ switch experiments without translation inhibitors (gray bar) or with translation inhibitors, cycloheximide (black bars), or puromycin (striped bars). (C) AC when translation inhibitors cycloheximide (black bars) or puromycin (striped bars) are added to steady state MDCK monolayers without undergoing a $\mathrm{Ca}^{2+}$ switch. $(D)$ Summary of the $\% \mathrm{Rec}_{\text {for }}$ the Ca ${ }^{2+}$ switch with and without translation inhibitors, including the direct application of translation inhibitors to the steady-state monolayers. Scale bars, $20 \mu \mathrm{m}$. Error bars represent mean \pm SEM based on five cells from three independent experiments. $\left(^{*}\right) P<0.05$.

expression levels during any stages of the $\mathrm{Ca}^{2+}$ switch experiment with or without translation inhibitors (Supplemental Fig. 2). These data demonstrate that de novo protein synthesis is specifically required for epithelial adherens junction complex assembly but not maintenance and that this mechanism does not significantly alter the total cellular levels of the adherens junction complex proteins E-cadherin, $\beta$-catenin, or $\beta$-actin.

\section{The $\beta$-actin mRNA zipcode regulates epithelial cell-cell contact-stimulated $\boldsymbol{\beta}$-actin monomer synthesis}

Having established that new protein synthesis and the $\beta$-actin mRNA 3' UTR are required for normal epithelial adherens junction assembly, we investigated the spatial distribution of $\beta$-actin monomer synthesis sites in MDCK cells expressing TC-GFP- $\beta$-actin 3 h post-contact using the $\mathrm{Ca}^{2+}$ switch method and $\beta$-actin translation site imaging (Fig. 3). In MDCK cells expressing full-length TC-GFP- $\beta$-actin, $\beta$-actin monomer synthesis is stimulated throughout the cytoplasm out to and including cell-cell contact sites $3 \mathrm{~h}$ post-contact (Fig. 3A, FL, $\beta$-actin). In contrast, deleting the $\beta$-actin $3^{\prime}$ UTR or masking the $\beta$-actin mRNA zipcode with $\beta$-actin zipcode antisense oligonucleotides significantly decreases cellcell contact-localized $\beta$-actin monomer synthesis while increasing perinuclear-localized monomer synthesis $3 \mathrm{~h}$ postcontact (Fig. 3A, $\Delta 3^{\prime}$ UTR $\beta$-actin and FL $\beta$-actin $+\beta$-actin zipcode AS). Importantly, adding $\beta$-actin mRNA zipcode antisense oligonucleotides has no effect on $\beta$-actin mRNA transcription site activation but does reduce $\beta$-actin mRNA reporter targeting to epithelial cell-cell contact sites (Supplemental Fig. 3). In fact, accumulation of GFP- $\beta$-actin at cellcell contact sites requires $\beta$-actin mRNA zipcode sequence (Supplemental Fig. 4). In contrast, $\beta$-actin mRNA zipcode sense oligonucleotides increase the number of contact localized $\beta$-actin monomer synthesis sites $3 \mathrm{~h}$ post-contact (Fig. $3 \mathrm{~A}, \mathrm{FL}, \beta$-actin $+\beta$-actin zipcode sense). To quantify the 

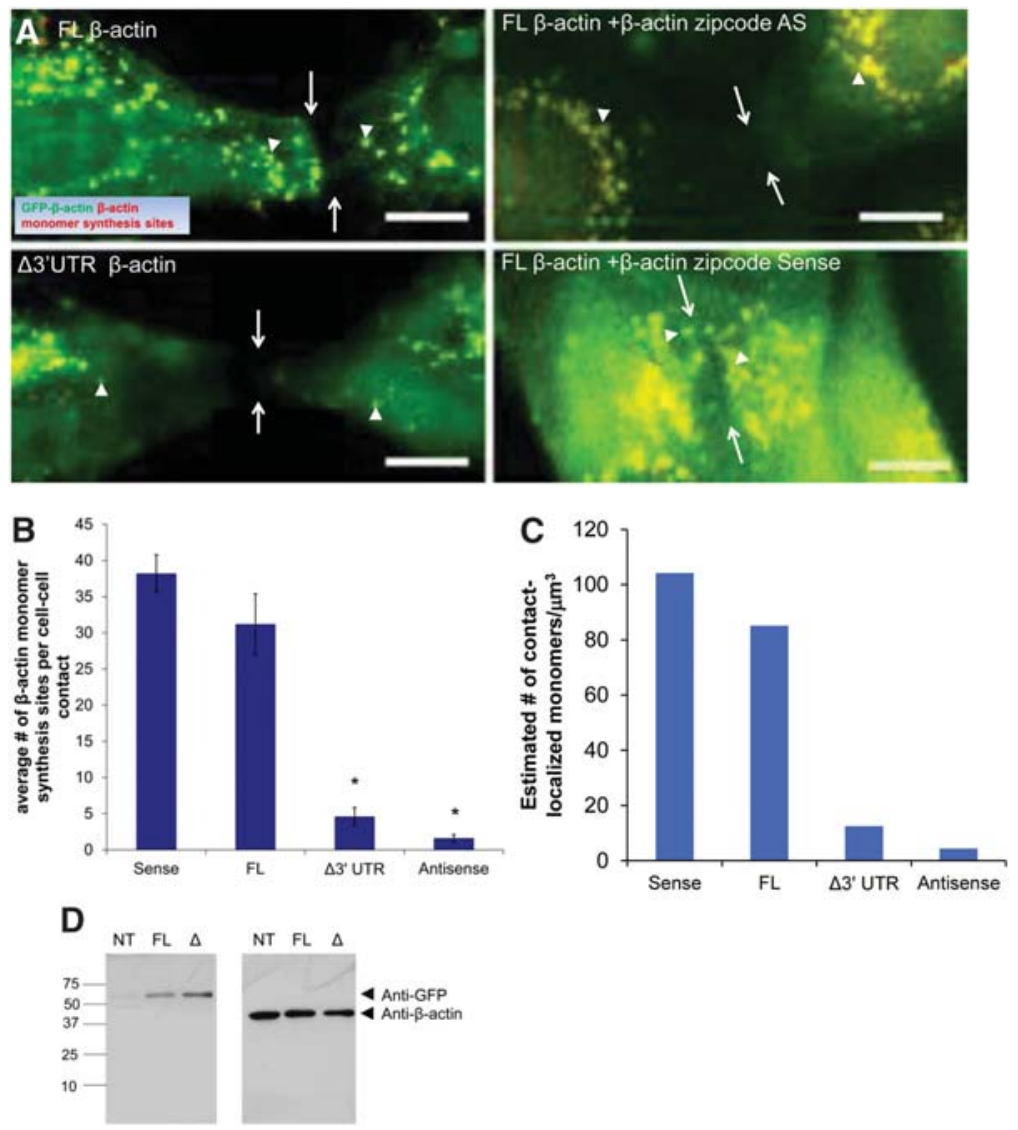

FIGURE 3. Epithelial cell-cell contact stimulates $\beta$-actin mRNA zipcode-mediated local monomer synthesis. (A) De-convolved epifluorescence images of a single plane of MDCK cells after $3 \mathrm{~h}$ in $\mathrm{Ca}^{2+}$ recovery media stained for de novo $\beta$-actin monomer synthesis (red) and mature GFP- $\beta$ actin (green). Top left: Untreated MDCK cells expressing FL $\beta$-actin (FL $\beta$-actin). Bottom left: Untreated MDCK cells expressing $\beta$-actin with a deleted $3^{\prime}$ UTR ( $\Delta 3^{\prime}$ UTR $\beta$-actin). Top right: MDCK cells expressing FL $\beta$-actin treated with $\beta$-actin zipcode antisense oligonucleotides during $\mathrm{Ca}^{2+}$ recovery (FL $\beta$-actin $+\beta$-actin zipcode AS). Bottom right: MDCK cells expressing FL $\beta$-actin treated with $\beta$-actin zipcode sense oligonucleotides (FL $\beta$-actin $+\beta$-actin Sense). Arrows show cell contact sites and arrowheads point to prominent $\beta$-actin synthesis sites near cell contact sites. $(B)$ Graph of the average number of $\beta$-actin monomer synthesis sites per cell contact. $(C)$ Estimated number of contact site-localized $\beta$-actin monomers synthesized during $3 \mathrm{~h}$ post-contact derived from the number of observed $\beta$-actin monomer synthesis sites for the experiments shown in panel $A$. (D) Western blots representing the amount of FL $\beta$-actin and $\Delta 3^{\prime}$ UTR $\beta$-actin being stably expressed in MDCK cells. Scale bars, $10 \mu \mathrm{m}$. Error bars represent mean \pm SEM based on five cells from three independent experiments. $\left(^{*}\right) P<0.001$.

difference in the number of contact localized $\beta$-actin monomer synthesis sites, we performed $\mathrm{Ca}^{2+}$ switch experiments in our MDCK cell lines and counted the number of translation sites in a fixed volume at cell-cell contacts (Fig. 3B). In sense-treated and -untreated full-length TC-GFP- $\beta$-actin-expressing cells, there were approximately sevenfold more contact localized $\beta$-actin translation sites compared to antisensetreated full-length and $\Delta 3^{\prime}$ UTR TC-GFP- $\beta$-actin-expressing cells (Fig. 3B). Since $\sim 20 \%$ of the $\beta$-actin expressed in our stable cell lines is from our reporter, we used the observed number of $\beta$-actin translation sites $3 \mathrm{~h}$ post-contact to estimate the theoretical number of monomers synthesized per unit volume at cell-cell contact sites (Fig. 3C,D; see Materials and
Methods). These data demonstrate that the $\beta$-actin mRNA zipcode is required to stimulate epithelial cell-cell contactlocalized $\beta$-actin monomer synthesis $3 \mathrm{~h}$ post-contact.

\section{The $\beta$-actin mRNA zipcode is required for epithelial adherens junction complex assembly but not maintenance}

Having established the $\beta$-actin mRNA $3^{\prime}$ UTR-localized zipcode sequence is required for cell-cell contact-stimulated monomer synthesis, we investigated the effects of $\beta$-actin mRNA zipcode antisense oligonucleotide-induced $\beta$-actin monomer synthesis delocalization during epithelial adherens junction assembly and maintenance. Adherens junction assembly was investigated using the $\mathrm{Ca}^{2+}$ switch method, E-cadherin indirect immunofluorescence, GFP- $\beta$-actin fluorescence, and asymmetry coefficient analysis in TC-GFP- $\beta$-actin-expressing MDCK cells (Fig. 4). Under normal conditions, E-cadherin and $\beta$-actin colocalize at cell-cell contact sites and within the perinuclear cytoplasm in steady-state epithelial monolayers (Fig. 4A, FL SS). After $1 \mathrm{~h}$ in low $\mathrm{Ca}^{2+}$ media, the epithelial cell monolayer is disassembled, and there is little E-cadherin/ $\beta$-actin colocalization in the peripheral cytoplasm (Fig. 4A, FL LC). After $180 \mathrm{~min}$ in $\mathrm{Ca}^{2+}$ recovery media, E-cadherin and $\beta$-actin recover their steady-state distributions, with strong colocalization observed at cell-cell contact sites and in the perinuclear cytoplasm within an organized epithelial monolayer (Fig. 4A, FL Rec 180). In contrast, in the $\Delta 3^{\prime}$ UTR TC-GFP- $\beta$-actin MDCK cells after $180 \mathrm{~min}$ in $\mathrm{Ca}^{2+}$ recovery media, $\beta$-actin is diffusely localized throughout the entire cytoplasm, and E-cadherin is also diffusely localized with no obvious cell-cell contact site localization (Fig. 4A, $\Delta 3^{\prime}$ UTR Rec 180). To investigate adherens junction assembly with greater time resolution, we performed $\mathrm{Ca}^{2+}$ switch experiments and asymmetry coefficient analysis on samples fixed at various time points in the MDCK cells expressing full-length or $\Delta 3^{\prime}$ UTR TC-GFP- $\beta$-actin (Fig. 4B). The full-length TC-GFP- $\beta$-actin-expressing cells exhibit $10 \%$ of the steady-state adherens junction levels after 1 $\mathrm{h}$ in low $\mathrm{Ca}^{2+}$ media, then progressively assemble adherens junctions after switching to $\mathrm{Ca}^{2+}$ recovery media, with $40 \%$ recovery at $1 \mathrm{~h}, 75 \%$ recovery at $2.5 \mathrm{~h}$, and $100 \%$ recovery 


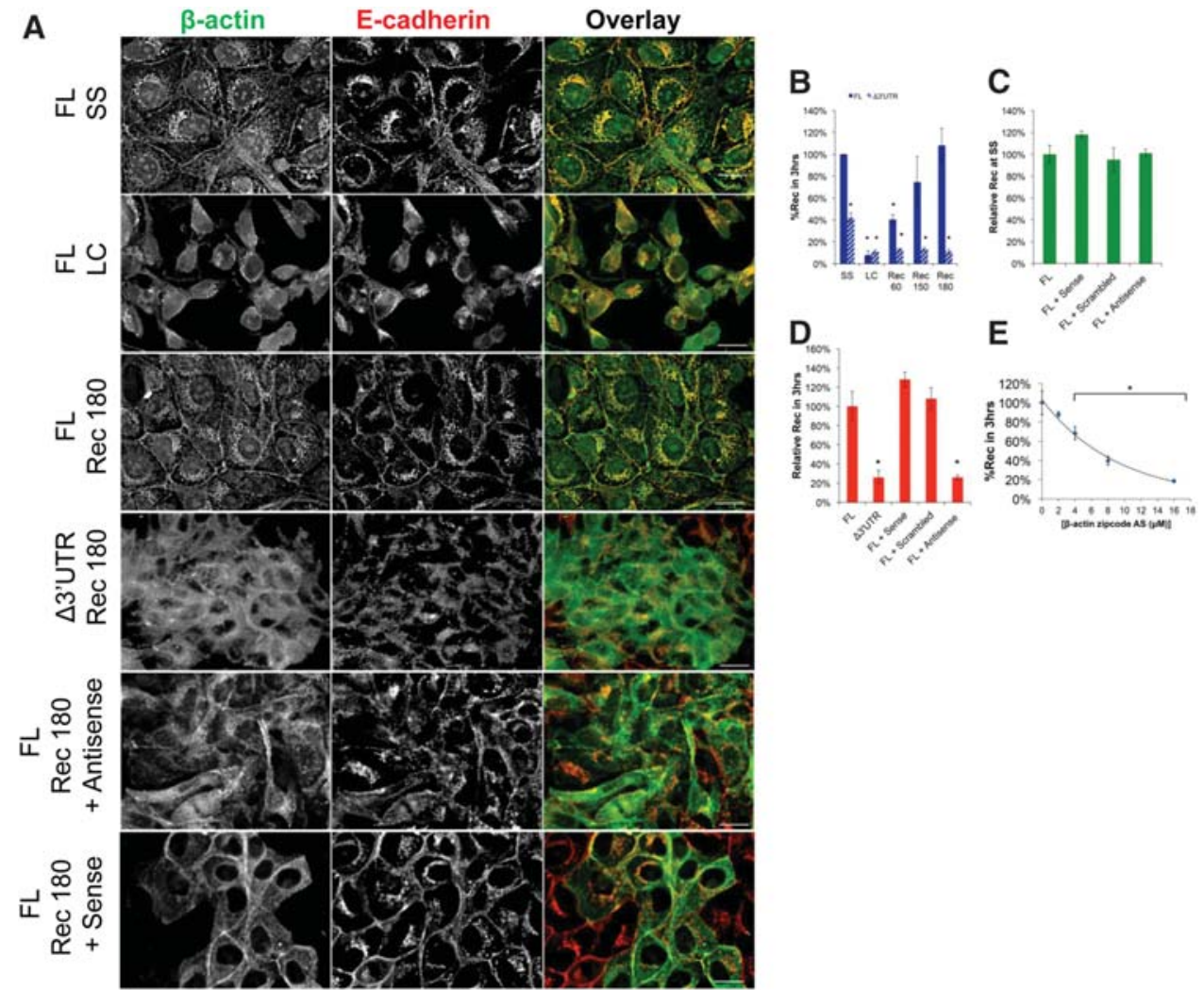

FIGURE 4. Contact-localized $\beta$-actin monomer synthesis stimulates epithelial AJ assembly. De-convolved epifluorescence images of a single plane of MDCK cells during a $\mathrm{Ca}^{2+}$ switch experiment with $\beta$-actin (green) labeled with GFP and E-cadherin (red) labeled by immunofluorescence. AJ complexes are identified by $\beta$-actin/E-cadherin colocalization (yellow) at cell contact sites. (A) Images are of MDCK cells in a monolayer at steady state expressing FL $\beta$-actin (FL SS), $1 \mathrm{~h}$ in low $\mathrm{Ca}^{2+}$ media (FL LC), and $3 \mathrm{~h}$ post-Ca ${ }^{2+}$ switch experiment (FL Rec 180). MDCK cells expressing $\Delta 3^{\prime}$ UTR $\beta$ actin are shown after $3 \mathrm{~h}$ in recovery media $\left(\Delta 3^{\prime}\right.$ UTR Rec 180$)$. Additionally, MDCK cells were treated with either zipcode antisense (FL Rec $180+$ Antisense) or sense (FL Rec $180+$ Sense) oligonucleotides during the recovery of a $\mathrm{Ca}^{2+}$ switch experiment. (B) Graph representing the \%Rec throughout various time points during a $\mathrm{Ca}^{2+}$ switch experiment in cells either expressing FL $\beta$-actin (solid blue) or $\Delta 3^{\prime}$ UTR $\beta$-actin (striped blue). (C) \%Rec of MDCK cells expressing FL $\beta$-actin treated with antisense, sense, and scrambled oligonucleotides for $3 \mathrm{~h}$ at SS. Measurements were normalized relative to untreated FL $\beta$-actin expressing cells. (D) Graph of the relative \%Rec of MDCK cells treated with antisense, sense, and scrambled oligonucleotides. This is the quantification for the phenotype observed in panel $A$. (E) Dose-dependent curve measuring the \%Rec relative to the concentration of zipcode-specific antisense oligonucleotides $3 \mathrm{~h}$ post-Ca ${ }^{2+}$ switch experiment. Scale bars, $20 \mu \mathrm{m}$. Error bars show means \pm SEM based on five cells in three independent experiments. $\left(^{*}\right) P<0.05$.

by $3 \mathrm{~h}$ (Fig. 4B, solid bars; Supplemental Fig. 5). In contrast, the $\Delta 3^{\prime}$ UTR MDCK cells exhibit $10 \%$ recovery after $1 \mathrm{~h}$ in low $\mathrm{Ca}^{2+}$ media but then remain near $10 \%$ recovery for the next $3 \mathrm{~h}$, even after the switch to $\mathrm{Ca}^{2+}$ recovery media (Fig. $4 \mathrm{~B}$, striped bars). Together, these data demonstrate that the $\beta$-actin $3^{\prime}$ UTR is necessary to assemble epithelial adherens junction complexes $3 \mathrm{~h}$ post-contact. To investigate the extent to which the phenotype observed in the $\Delta 3^{\prime}$ UTR TC-GFP- $\beta$ actin-expressing cells is mediated by the $\beta$-actin mRNA zipcode, we tested the effects of adding $\beta$-actin mRNA zipcode antisense or sense oligonucleotides to $\mathrm{Ca}^{2+}$ recovery media following epithelial cell-cell contact (Fig. 4A, FL Rec $180+$ Antisense and FL Rec $180+$ Sense). Adding $\beta$-actin mRNA zipcode antisense oligonucleotides to $\mathrm{Ca}^{2+}$ recovery media impairs monolayer assembly and causes $\beta$-actin and E-cadherin to diffusely localize throughout the cytoplasm. Additionally, there is little E-cadherin/ $\beta$-actin colocalization at cell-cell contact sites, as the cells appear elongated, and areas of the culture dish exhibit significant cellular overlap (Fig. 4A, Rec $180+$ Antisense). In contrast, adding $\beta$-actin mRNA zipcode sense oligonucleotides to $\mathrm{Ca}^{2+}$ recovery media stimulates monolayer assembly and causes $\beta$-actin and E-cadherin to localize at cell-cell contact sites with significant levels of colocalization observed (Fig. 4A, Rec $180+$ Sense). Significantly, wild-type MDCK cells treated with $\beta$-actin mRNA zipcode sense, scrambled, or antisense oligonucleotides exhibit similar phenotypes in terms of adherens junction assembly to those observed in our TC-GFP- $\beta$-actin-expressing MDCK cells, demonstrating the importance of spatially regulating $\beta$-actin monomer synthesis in wild-type MDCK cells (Supplemental Fig. 6). Importantly, MDCK cells at steady state treated with sense, scrambled, or antisense $\beta$ actin mRNA zipcode oligonucleotides for $3 \mathrm{~h}$ maintain their adherens junction complexes, demonstrating that contact- 
localized $\beta$-actin monomer synthesis is not required to maintain epithelial adherens junctions, confirming the results obtained with global translation inhibitors in Figure 2 (Fig. 4C; Supplemental Fig. 7). In contrast, treating TC-GFP- $\beta$-actin MDCK cells with $\beta$-actin mRNA zipcode antisense oligonucleotides during the $\mathrm{Ca}^{2+}$ recovery inhibits adherens junction assembly to a similar extent as $3^{\prime}$ UTR deletion, while the control scrambled and sense oligonucleotides have no effect on junction assembly (Fig. 4A,D; Supplemental Fig. $8)$. Lastly, to investigate the extent to which the $\beta$-actin mRNA zipcode regulates epithelial adherens junction assembly, we determined the dose response curve for adherens junction assembly as a function of the concentration of $\beta$ actin mRNA zipcode antisense oligonucleotides during $\mathrm{Ca}^{2+}$ recovery. As demonstrated in Figure 4E, increasing the concentration of $\beta$-actin mRNA zipcode antisense oligonucleotides decreases epithelial adherens junction assembly in a dose-dependent manner. Interestingly, perturbing $\beta$ actin mRNA zipcode function in MDCK cells significantly alters their epithelial morphology, causing them to elongate. For example, $\beta$-actin 3' UTR deletion, masking the $\beta$-actin mRNA zipcode, or inhibiting the signaling pathways that drive mRNA zipcode-mediated targeting, or spatially localized translation, all significantly increase the length-to-width ratio of our MDCK cell lines (Supplemental Fig. 9). These data demonstrate that a functional $\beta$-actin mRNA zipcode is required to assemble but not maintain epithelial adherens junction complexes.

\section{The $\beta$-actin mRNA zipcode is required to localize active RhoA, the signal driving $\beta$-actin mRNA targeting, to epithelial cell-cell contact sites}

Typically, epithelial cells switch from contact initiation to contact expansion in response to down-regulation of Rac1 activity and contact localization of active RhoA, the signal required for zipcode mRNA targeting. In fact, active RhoA is a component of maturing adherens junction assembly sites. Consequently, we investigated the effects of $\beta$-actin mRNA zipcode antisense oligonucleotide-induced $\beta$-actin monomer synthesis delocalization on contact-localized RhoA activity using a FRET-based RhoA activity biosensor (Fig. 5). RhoA activity was assessed in MDCK cells expressing a bimolecular FRET RhoA biosensor during $\mathrm{Ca}^{2+}$ switch experiments (Fig. 5B). At steady state, active RhoA is diffusely localized throughout the cytoplasm (Fig. 5B, SS). Following $\mathrm{Ca}^{2+}$ recovery, active RhoA is localized to cell-cell contact sites in the untreated and $\beta$-actin mRNA zipcode sense oligonucleotide-treated MDCK cells (Fig. 5B, Rec 280 and Rec + Sense). In contrast, following the switch to $\mathrm{Ca}^{2+}$ recovery media containing $\beta$-actin mRNA zipcode antisense oligonucleotides, active RhoA is localized throughout the cytoplasm, failing to significantly accumulate at cell-cell contact sites (Fig. 5B, Rec + Antisense). Quantifying the percent of cells with active
RhoA localized to contact site plasma membranes confirms low levels of active RhoA at cell contacts at steady state and after $1 \mathrm{~h}$ in low $\mathrm{Ca}^{2+}$ media, with a progressive localization of active RhoA to cell contact beginning at $30 \mathrm{~min}$ and peaking around $4.5 \mathrm{~h}$ post-contact (Fig. 5C). Interestingly, comparing the percent of cells with contact-localized active RhoA in the $\beta$-actin mRNA zipcode sense and antisense oligonucleotidetreated samples demonstrates delocalizing $\beta$-actin monomer synthesis with $\beta$-actin mRNA zipcode antisense oligonucleotides significantly reduces localization of active RhoA to cellcell contact sites (Fig. 5D). These data demonstrate that the $\beta$-actin mRNA zipcode is required to localize the signal required for $\beta$-actin mRNA targeting, active RhoA, to cell-cell contact sites.
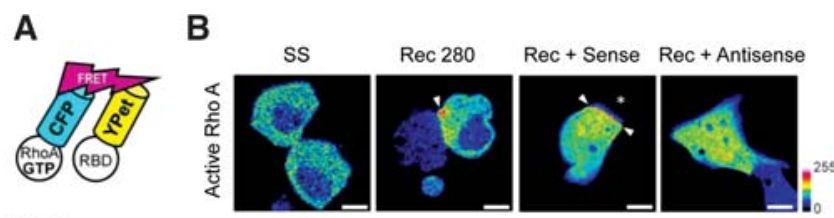

RhoA biosensor
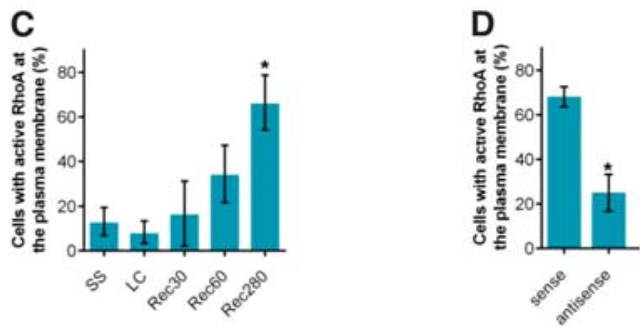

FIGURE 5. Active-RhoA accumulates and persists at cell contact sites during the contact expansion stage of epithelial AJ assembly. An intermolecular FRET-based RhoA biosensor was expressed in MDCK cells to visualize the subcellular localization of active-RhoA following epithelial cell contact. $(A)$ The intermolecular FRET-based RhoA biosensor consists of RhoA tagged to CFP (donor) and the amino acids 7-89 of Rhotekin fused to Ypet (acceptor). The activation-dependent binding of the donor and acceptor was visualized by sensitized-emission FRET microscopy. (B) RhoA activity is targeted to contact site-localized plasma membrane during cell junction formation. Under steady state (SS) conditions in confluent epithelial cell monolayers, active-RhoA is uniformly distributed throughout the cytoplasm. During junction assembly following incubation in $\mathrm{Ca}^{2+}$ recovery media (Rec 280), activeRhoA is targeted to regions of the plasma membrane adjacent to sites of cell contact. MDCK cells expressing the RhoA biosensor were treated as indicated, and RhoA activity was imaged by sensitized-emission microscopy. Sense oligonucleotides illustrated contact-localized activeRhoA at the cell contact (Rec + Sense). Antisense oligomers targeting $\beta$-actin zipcode mRNA prevent recruitment of active RhoA to the plasma membrane (Rec + Antisense). MDCK cells expressing the RhoA biosensor were treated as indicated, and RhoA activity was imaged between 1 and $2 \mathrm{~h}$ following the return to the $\mathrm{Ca}^{2+}$ recovery media. The images were pseudocolored according to the scale to the right of the figure. Scale bars, $5 \mu \mathrm{m}$. Arrowheads indicate regions of active RhoA at the plasma membrane. $(C)$ Quantification of RhoA activity distribution during cell junction formation. (*) $P<0.05$ vs. LC. Error bars show means \pm SEM based on a minimum of 37 cells. $(D)$ The distribution of RhoA activity was quantified in cells treated as indicated. $\left(^{*}\right) P<$ 0.05 vs. WT sense. Error bars show means \pm SEM based on a minimum of 17 cells. 
Inhibiting the Src kinase signal required to initiate $\boldsymbol{\beta}$-actin translation delocalizes $\boldsymbol{\beta}$-actin monomer synthesis and perturbs adherens junction assembly

During transcription, ZBP1 interacts with the $\beta$-actin mRNA zipcode to inhibit translation prior to mRNA targeting. Translation is initiated when ZBP1 is phosphorylated by Src, causing dissociation of the translationally inhibited ZBP1/ $\beta$-actin mRNA complex (Huttelmaier et al. 2005). Consequently, we investigated the distribution of $\beta$-actin monomer synthesis following epithelial cell-cell contact in MDCK cells treated with increasing concentrations of the Src inhibitor (Fig. 6; Supplemental Fig. 10). At low concentrations of Src inhibitor, $\beta$-actin monomer synthesis is active throughout the cytoplasm out to and including cell-cell contact sites $3 \mathrm{~h}$ post-contact (Fig. 6A, $0 \mathrm{nM} \mathrm{Src} \mathrm{Inh} \mathrm{and} 44 \mathrm{nM} \mathrm{Src} \mathrm{Inh).} \mathrm{Con-}$ sequently, at low concentrations of the Src inhibitor, adherens junction assembly proceeds normally (Fig. 6B, $0 \mathrm{nM}$ Src Inh and $44 \mathrm{nM}$ Src Inh). In contrast, at higher concentrations of the Src inhibitor, $\beta$-actin monomer synthesis is significantly reduced, with low levels of monomer synthesis observed throughout the cytoplasm and at cell-cell contact sites $3 \mathrm{~h}$

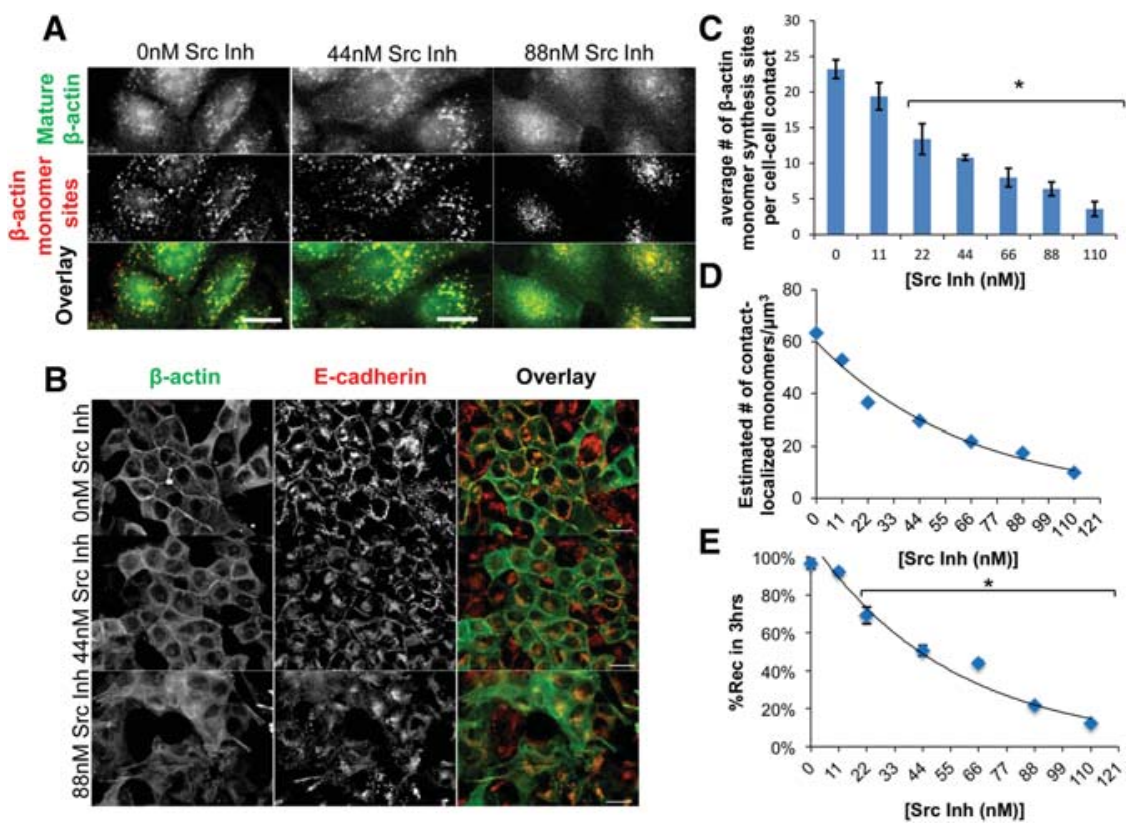

FIGURE 6. Inhibiting Src activity decreases contact-localized $\beta$-actin monomer synthesis to perturb epithelial adherens junction assembly. $(A)$ De-convolved epifluorescence images of MDCK cells $3 \mathrm{~h}$ after the return to $\mathrm{Ca}^{2+}$ recovery media without (0 $\mathrm{nM} \mathrm{Src} \mathrm{Inh)} \mathrm{or} \mathrm{with} \mathrm{(44}$ $\mathrm{nM}$ Src Inh and $88 \mathrm{nM}$ Src Inh) Src-1 inhibitor. $\beta$-actin monomer synthesis sites are in red and mature $\beta$-actin is in green. Scale bars, $10 \mu \mathrm{m}$. (B) De-convolved epifluorescence images of MDCK cells $3 \mathrm{~h}$ post-Ca ${ }^{2+}$ experiment illustrating $\beta$-actin (green) and E-cadherin (red) without ( $0 \mathrm{nM}$ Src Inh) or with (44 nM Src Inh or $88 \mathrm{nM}$ Src Inh) Src-1 inhibitor. Scale bars, $20 \mu \mathrm{m}$. $(C)$ Graph of the average number of $\beta$-actin monomer synthesis sites per cell contact. $(D)$ Dosedependent curve shows the effects of increased concentrations of Src-1 inhibitor on the estimated number of contact-localized $\beta$-actin monomers. Scale bars, $10 \mu \mathrm{m}$. (E) Dose-dependent curve showing the relationship between increased Src-1 inhibitor on the \%Rec of MDCK monolayer in $3 \mathrm{~h}$ after a $\mathrm{Ca}^{2+}$ experiment. Error bars mean \pm SEM based on five cells in three independent experiments. $\left(^{*}\right) P<0.05$.

\section{DISCUSSION}

\section{The $\beta$-actin mRNA $3^{\prime}$ UTR and zipcode sequence regulate epithelial adherens junction assembly but not maintenance}

The $\beta$-actin mRNA zipcode is a $3^{\prime}$ UTRlocalized sequence responsible for regulating mRNA targeting and monomer synthesis through reversible binding to the translation inhibitor ZBP1 (Kislauskis et al. 1994; Huttelmaier et al. 2005; Rodriguez et al. 2006). Translationally inhibited zipcode-containing mRNAs localize to the peripheral cytoplasm in response to active RhoA (Latham et al. 2001). Localized translation is initiated by Src-mediated phosphorylation of ZBP1, causing mRNA/ZBP1 complex dissociation (Huttelmaier et al. 2005). Interestingly, the mRNAs for the adherens junction proteins, E-cadherin, $\beta$-catenin, and $\beta$-actin contain putative zipcode sequences indicating adherens junction complex assembly may be regulated by spatially regulated protein synthesis (Rodriguez et al. 2008). In fact, ZBP1 pull-down assays confirm interactions between this translation regulator and the adherens junction mRNAs E-cadherin, $\beta$-catenin, and $\beta$-actin ( $\mathrm{Gu}$ et al. 2009). Consequently, we investigated the roles of de novo protein synthesis, the $\beta$ - 
actin $3^{\prime}$ UTR, and the $\beta$-actin mRNA zipcode sequence during epithelial adherens junction complex assembly and maintenance. Importantly, inhibiting translation with cycloheximide or puromycin, deleting the $\beta$-actin $3^{\prime}$ UTR, or masking $\beta$-actin mRNA zipcode/ZBP1 binding with $\beta$-actin mRNA zipcode antisense oligonucleotides all significantly inhibit de novo epithelial adherens junction assembly. In fact, $\beta$-actin mRNA zipcode antisense oligonucleotides inhibit adherens junction assembly in a dose-dependent manner, demonstrating that the $\beta$-actin mRNA zipcode can control adherens junction complex assembly following epithelial cell contact. In contrast, inhibiting translation with cycloheximide or puromycin or masking $\beta$-actin mRNA zipcode/ZBP1 binding with $\beta$-actin zipcode antisense oligonucleotides in steady-state monolayers has no immediate effect on adherens junction complex maintenance. These data demonstrate that the $\beta$-actin mRNA zipcode is required for epithelial adherens junction assembly but not maintenance. Interestingly, E-cadherin siRNA knockdown (another zipcode-containing mRNA) does not cause disassembly of established adherens junction complexes but does prevent de novo adherens junction assembly, demonstrating that E-cadherin expression is also required for epithelial adherens junction assembly but not maintenance (Capaldo and Macara 2007). Together, these data demonstrate a critical role for zipcode-containing mRNAs during epithelial adherens junction assembly but not maintenance.

\section{The $\beta$-actin mRNA zipcode mediates spatially localized $\beta$-actin monomer synthesis to locally regulate $\beta$-actin filament polymerization at cell-cell contact sites}

As discussed above, the $\beta$-actin mRNA zipcode is required for contact-localized $\beta$-actin monomer synthesis (Rodriguez et al. 2006). Consequently, we determined the spatial distribution of $\beta$-actin monomer synthesis in untreated fulllength TC-GFP- $\beta$-actin, $\beta$-actin mRNA zipcode antisense oligonucleotide-treated full-length TC-GFP- $\beta$-actin, $\beta$-actin mRNA zipcode sense oligonucleotide-treated full-length TC-GFP- $\beta$-actin, and $\Delta 3^{\prime}$ UTR TC-GFP- $\beta$-actin-expressing MDCK cells. Incredibly, the untreated and sense-treated cells exhibited significant levels of cell-cell contact-localized $\beta$-actin monomer synthesis $3 \mathrm{~h}$ post-contact. In contrast, $\beta$-actin mRNA zipcode antisense oligonucleotide-treated and $\Delta 3^{\prime}$ UTR $\beta$-actin-expressing cells exhibit significant increases in the level of perinuclear localized $\beta$-actin monomer synthesis and significant decreases in cell-cell contact-localized monomer synthesis $3 \mathrm{~h}$ post-contact. Extrapolating the observed levels of $\beta$-actin monomer synthesis over the 3 -h recovery period demonstrates that untreated full-length $\beta$-actin expressing- $\left(\sim 85\right.$ monomers $\left./ \mu \mathrm{m}^{3}\right)$ and $\beta$-actin mRNA zipcode sense oligonucleotide-treated $\left(\sim 100\right.$ monomers $\left./ \mu \mathrm{m}^{3}\right)$ MDCK cells can synthesize sufficient $\beta$-actin to exceed the critical concentration for actin filament polymerization from barbed ends (61 monomers $/ \mu \mathrm{m}^{3}$ ) (Bonder et al. 1983).
In contrast, $\beta$-actin mRNA zipcode antisense oligonucleotide-treated $\left(\sim 5\right.$ monomers $\left./ \mu \mathrm{m}^{3}\right)$ and $\Delta 3^{\prime}$ UTR $\beta$-actinexpressing $\left(\sim 15\right.$ monomers $\left./ \mu \mathrm{m}^{3}\right)$ MDCK cells do not synthesize sufficient $\beta$-actin to exceed the critical concentration for actin filament polymerization from barbed ends. Consequently, linear actin filament assembly at cell-cell contact sites is high in the untreated full-length $\beta$-actin-expressing and sense-treated full-length $\beta$-actin-expressing MDCK cells and low in the antisense-treated full-length $\beta$-actin-expressing and $\Delta 3^{\prime}$ UTR $\beta$-actin expressing MDCK cells. Taken together, these data demonstrate that a functional $\beta$-actin mRNA zipcode is required to synthesize sufficient spatially localized $\beta$ actin monomers to stimulate barbed end actin filament polymerization at cell-cell contact sites.

\section{Perturbing $\beta$-actin mRNA zipcode activity causes a dominant negative epithelial adherens junction assembly phenotype}

It is well established that the extent of actin filament polymerization depends on the local concentration of available monomer (Lanni and Ware 1984; Cao et al. 1993). In fact, actin filament polymerization from barbed ends requires at least a fivefold lower critical concentration of available monomer than polymerization from pointed ends (Pollard and Mooseker 1981; Bonder et al. 1983). The geometry of actin filament arrays is determined by the specific actin binding proteins localized near polymerization sites; for example, Arp $2 / 3$ complexes stimulate branched filament array assembly, and $\mathrm{mDia} /$ formin proteins stimulate linear filament array assembly (Chhabra and Higgs 2007). In non-contacting motile cells, persistent directional movement requires $\beta$-actin mRNA zipcode-mediated leading edge localized $\beta$-actin translation to provide a source of available monomer and spatially localized Arp2/3 complex activity to stimulate branched filament array assembly to specify the direction of lamellar protrusion (Bailly et al. 1998; Shestakova et al. 2001). In contrast, following epithelial cell-cell contact, branched actin filament arrays are disassembled by $a$-catenin-mediated inhibition of Arp $2 / 3$ complex activity, significantly decreasing lamellar protrusion (Drees et al. 2005). Subsequently, linear actin filament arrays are assembled as a result of $\mathrm{mDia}$ and/or formin activity, providing the cytoskeletal scaffold for E-cadherin anchoring at cell-cell contact sites required for adherens junction assembly (Sahai and Marshall 2002; Kobielak et al. 2004). Also, chemically perturbing actin filament polymerization properties with cytochalasins potently inhibits adherens junction assembly in contacting epithelial cells (Vasioukhin et al. 2000). Consequently, the amount and types of actin filament arrays assembled is determined by the local availability of actin monomer coupled to the spatial and temporal regulation of actin binding protein activity.

The importance of spatially regulating $\beta$-actin monomer availability following epithelial cell-cell contact is illustrated by the dominant negative adherens junction assembly 
phenotype observed in our $\Delta 3^{\prime}$ UTR $\beta$-actin reporter-expressing MDCK cells. This cell line expresses $\beta$-actin at similar levels as wild-type and full-length $\beta$-actin-expressing MDCK cells since the reporters contain the endogenous $\beta$-actin promoter and, therefore, are subject to the endogenous feedback inhibition pathway that controls the total $\beta$-actin transcript number in living cells (Ballestrem et al. 1998). We estimate that $\sim 20 \%$ of the $\beta$-actin transcribed in our $\Delta 3^{\prime}$ UTR $\beta$-actin MDCK cell line lacks the $\beta$-actin zipcode mislocalizing their monomer synthesis sites to the perinuclear cytoplasm, with the remaining $80 \%$ of zipcode-containing transcripts maintaining their cell-cell contact-localized synthesis (Fig. 3). As a result, the final level of cell-cell contact site-localized $\beta$-actin monomer synthesis is significantly lower in the $\Delta 3^{\prime}$ UTR $\beta$-actin cells. As a consequence of lowering the level of cell-cell contact site-localized $\beta$-actin monomer synthesis, the total amount of available monomer at these sites decreases. This decrease in available monomer perturbs the timely assembly of linear actin filament arrays, and consequently, E-cadherin anchoring causing a dominant negative phenotype in terms of adherens junction assembly. In fact, we can recapitulate this dominant negative adherens junction assembly phenotype by inhibiting $\beta$-actin mRNA zipcode/ZBP1 interaction with $\beta$-actin mRNA zipcode antisense oligonucleotides. As seen in Figure 4, increasing the concentration of $\beta$-actin mRNA zipcode antisense oligonucleotides reduces adherens junction assembly in a dose-dependent manner. As a consequence, increasing the concentration of $\beta$-actin mRNA zipcode antisense oligonucleotides decreases the amount of monomer available at the contact site, slowing the rate of barbed end polymerization. This lowers the levels of linear actin filament array assembly at cell-cell contact sites, causing the observed adherens junction assembly defects (Fig. 4). Thus, we hypothesize that the function of the $\beta$-actin mRNA zipcode in contacting epithelial cells is to spatially localize $\beta$-actin monomer synthesis at cell-cell contact sites to establish and sustain the driving force for linear actin filament array assembly required for E-cadherin anchoring and epithelial adherens junction assembly.

\section{The signaling pathways that target and regulate the translation of zipcode mRNAs are required for epithelial adherens junction assembly}

As discussed previously, contact localization of active RhoA is required to target zipcode mRNAs to the cell periphery, and active Src is required to initiate translation of the targeted mRNAs (Latham et al. 2001; Huttelmaier et al. 2005). In fact, assessing the distribution of active RhoA using a FRET-based biosensor demonstrates active RhoA localized to cell-cell contact sites in untreated full-length TC-GFP- $\beta$-actin-expressing MDCK cells post-contact. Importantly, there is very little active RhoA localized to cell-cell contact sites in steady state MDCK cells and in antisense-treated full-length TC-GFP- $\beta$ actin-expressing cells post-contact. In contrast, there is strong localization of active RhoA to cell-cell contact sites in sensetreated full-length TC-GFP- $\beta$-actin-expressing MDCK cells post-contact. Moreover, the percentage of cells with cell-cell contact-localized active RhoA steadily increases post-contact. Incredibly, there is a significant decrease in the percentage of cells with cell-cell contact-localized active RhoA when MDCK cells treated with antisense oligonucleotides are compared to cells treated with sense oligonucleotides post-contact (Fig. 5). Together, these data demonstrate that the $\beta$-actin mRNA zipocode is required to localize the signal required for targeting zipcode-containing mRNAs to cell-cell contact sites during adherens junction assembly. Importantly, the active Src signal required to initiate translation of zipcodecontaining mRNAs regulates adherens junction assembly. Low concentrations of Src inhibitor cause a significant decrease in the amount of cell-cell contact-localized $\beta$-actin monomer synthesis. In contrast, high concentrations of Src inhibitor strongly inhibit $\beta$-actin monomer synthesis throughout the entire cytoplasm. Incredibly, the decrease in cell-cell contact-localized $\beta$-actin translation inversely correlates with epithelial adherens junction assembly, with significant junction assembly observed in the presence of low concentrations of Src inhibitor and progressively fewer junctions assembled in the presence of high concentrations of Src inhibitor (Fig. 6). Taken together, these data demonstrate that active Src is required to locally initiate $\beta$-actin monomer synthesis at cell-cell contact sites and increase the available $\beta$ actin monomer concentration to stimulate filament polymerization and adherens junction assembly.

\section{The $\beta$-actin mRNA zipcode integrates the RhoA and Src signaling pathways to spatially regulate actin cytoskeleton remodeling and stimulate epithelial adherens junction assembly}

Epithelial adherens junction assembly requires E-cadherinmediated actin filament remodeling from branched to linear filaments to decrease membrane protrusion and stabilize nascent junction complexes (Drees et al. 2005). A significant proportion of $\beta$-actin protein at the leading lamella prior to cell-cell contact and adherens junction assembly is posttranslationally arginylated, preventing tight packing and consequently favoring branched filament polymerization (Karakozova et al. 2006). In contrast, linear actin filaments, required to stabilize and anchor adherens junction complexes, are assembled from nonarginylated $\beta$-actin monomers (Saha et al. 2010). Consequently, we hypothesize that the monomer required for linear actin filament polymerization at cell contact sites during adherens junction assembly are products of locally translated $\beta$-actin. Intriguingly, we observe GFP- $\beta$-actin hotspots in close proximity to $\beta$-actin monomer synthesis sites post-contact. In fact, masking $\beta$-actin mRNA zipcode/ZBP1 interaction with $\beta$-actin mRNA zipcode antisense oligonucleotides in fibroblast cells is sufficient to delocalize actin filament polymerization sites (Shestakova et al. 
2001). Interestingly, the critical concentration for barbed end actin filament polymerization when converted to number of monomers per unit volume is 61 monomers $/ \mu \mathrm{m}^{3}$ (Bonder et al. 1983). Consequently, following de novo contact between untreated full-length $\left(\sim 100\right.$ monomers $\left./ \mu \mathrm{m}^{3}\right)$ or sense-treated $\left(\sim 85\right.$ monomers $\left./ \mu \mathrm{m}^{3}\right)$ epithelial cells, there are sufficient monomers to induce polymerization from the barbed end of the filament but not from the pointed end ( 2360 monomers $\left./ \mu \mathrm{m}^{3}\right)$. In contrast, following de novo contact between antisense-treated $\left(\sim 5\right.$ monomers $\left./ \mu \mathrm{m}^{3}\right)$ or $\Delta 3^{\prime}$ UTR- $(\sim 15$ monomers $/ \mu \mathrm{m}^{3}$ ) expressing epithelial cells there are insufficient monomers to induce polymerization from either the barbed or pointed end of the actin filament. Newly synthesized nonarginylated $\beta$-actin monomers, thus, stimulate linear filament polymerization to stabilize adherens junction complex assembly at cell-cell contact sites. These results agree with the observation that actin barbed end binding proteins such as Ena/Vasp or mDia/formin-1 regulate linear filament polymerization and, consequently, are required for adherens junction assembly (Sahai and Marshall 2002; Kobielak et al. 2004; Scott et al. 2006; Carramusa et al. 2007). Interestingly, although scrambled sequence oligonucleotides do not perturb adherens junction complex assembly, we observe $\beta$-actin mRNA zipcode sense oligonucleotides increase contact-localized monomer synthesis and adherens junction assembly. We propose this effect may be due to an antisense-sense duplexmediated regulation of $\beta$-actin transcript levels in cells (Rosok and Sioud 2004). In this model, the sense oligonucleotides sequester endogenous antisense oligonucleotides, effectively increasing the available template mRNA available for translation. In addition to $\beta$-actin, ZBP1 associates with mRNAs coding for other proteins of the adherens junction complex. Notable among them are E-cadherin and $\beta$-catenin (Rodriguez et al. 2008; Gu et al. 2009, 2012). Consequently, we postulate mRNA zipcode/ZBP1 interactions regulate epithelial adherens junction complex assembly by converting the signals generated by E-cadherin homophilic adhesion into site-specific adherens junction complex protein translation. In this report, we provide evidence demonstrating spatially regulated $\beta$-actin monomer synthesis hardwires E-cadherin homophilic contact-induced RhoA and Src signals into localized actin filament remodeling to stimulate adherens junction complex assembly at epithelial cell-cell contact sites.

\section{MATERIALS AND METHODS}

\section{Plasmids and antibodies}

The following antibodies were used for immunofluorescence staining: anti-E-cadherin (1:250; BD Biosciences), anti- $\beta$-catenin (1:250; BD Biosciences), anti- $\alpha$-catenin (1:250; Sigma Aldrich), antiPhospho-Src Tyr416 (1:50; Cell Signaling), Cy5 conjugated donkey anti-rabbit (1:800; Jackson Laboratory), and Cy3 conjugated goat anti-mouse (1:1000; Invitrogen). In addition, Alexa488 conjugated phalloidin (1:40; Invitrogen) was used to stain actin filaments.
pRBD-YPet was constructed by inserting the cDNA sequence encoding aa 7-89 of mouse rhotekin into the EcoRI/BamHI sites of pYPet-N1. The YPet sequence was amplified from pCEP4YPetMAMM (Addgene plasmid 14032) and cloned into AgeI/NotI sites of pEYFP-N1 (Clontech), generating the pYPet-N1 (Nguyen and Daugherty 2005). The pECFP-RhoA construct was previously described (Picard et al. 2009).

\section{Cell culture, transfection, and calcium switch}

MDCK (Madin-Darby canine kidney) epithelial cells were cultured in DMEM containing 10\% FBS with antibiotics. Cells were transfected with reporter plasmids using Lipofectamine 2000 (Invitrogen) according to the manufacturer's guidelines. G418 sulfate was used to select transfected clones of the full-length- and $\Delta 3^{\prime}$ UTR $\beta$-actin-expressing MDCK cell lines. For $\mathrm{Ca}^{2+}$ switching, cells were plated on glass coverslips until an 85\%-95\% confluent monolayer assembled. These monolayers were incubated with DMEM with 2-4 mM EGTA for $1 \mathrm{~h}$. To begin cell contact, the cells were returned to $\mathrm{Ca}^{2+}$-containing DMEM for $3 \mathrm{~h}$ (Volberg et al. 1986).

\section{$\beta$-actin mRNA zipcode oligonucleotide treatments}

Phosphorothioate modified antisense 5'-CGCAACTAAGTCATA GTC-3', sense 5'-GACTATGACTTAGTTGCG-3', and scrambled 5'-ACTGCAACGTCGTATACA-3' oligonucleotides were added to the cells in accordance with Shestakova et al. (2001). To determine the dose response curve for $\beta$-actin mRNA antisense oligonucleotides as a function of adherens junction assembly, MDCK cells were treated with $\mathrm{Ca}^{2+}$ recovery media containing $2 \mu \mathrm{M}, 4 \mu \mathrm{M}, 8$ $\mu \mathrm{M}$, or $16 \mu \mathrm{M}$ oligonucleotides once every $4 \mathrm{~h}$ for $12 \mathrm{~h}$ during $\mathrm{Ca}^{2+}$ switch experiments.

\section{Translation site imaging and quantification}

MDCK cells expressing FL $\beta$-actin or $\Delta 3^{\prime}$ UTR $\beta$-actin were plated at 300,000 cells per cover slip and incubated for $48 \mathrm{~h}$. The cells underwent a $\mathrm{Ca}^{2+}$ switch containing the biarsenical dye, FlAsH, for $1 \mathrm{~h} \mathrm{(2}$ mM EGTA, $0.9 \mu \mathrm{M}$ FlAsH, $12.5 \mu \mathrm{M}$ stain stock, in Reduced Media OptiMEM). Staining stock is $11.9 \mathrm{mM} \mathrm{EDT}_{2}$ in DMSO. After $1 \mathrm{~h}$ in low $\mathrm{Ca}^{2+}$ media with FlAsH, the cells were washed three times for 5 min each with $1 \times \mathrm{PBS}$, $\mathrm{pH} 7.4$, then returned to recovery media (DMEM containing high glucose, $1 \%$ pen/strep, and 10\% FBS) for $2.5 \mathrm{~h}$. Recovery was followed by treatment in a chase solution (1 $\mu \mathrm{M}$ ReAsH, $12.5 \mu \mathrm{M}$ stain stock, $100 \mu \mathrm{g} / \mathrm{mL}$ cycloheximide, and DMEM) for $30 \mathrm{~min}$. Cells were then de-stained for $10 \mathrm{~min}$ at $37^{\circ} \mathrm{C}$ with de-staining solution $(600 \mu \mathrm{M}$ de-stain stock and Reduced Media OptiMEM). De-stain stock is $9.9 \mu \mathrm{M}$ of BAL (2,3-dimercaptopropanol) in DMSO. They were washed three times for $5 \mathrm{~min}$ each with $1 \times \mathrm{PBS}$, $\mathrm{pH} 7.4$ and fixed with paraformaldehyde in $1 \times \mathrm{PBS}, \mathrm{pH}$ 7.4 for $20 \mathrm{~min}$. As a control to show these were, indeed, translation sites, $200 \mu \mathrm{g} / \mathrm{mL}$ of puromycin was added to the recovery media. If using antisense, sense, or scrambled, cells were kept in media containing the oligonucleotide until ready for fixation. For Src inhibitor experiments, the cells were treated with Src-1 inhibitor (Sigma) at various concentrations $(11 \mathrm{nM}, 22 \mathrm{nM}, 44 \mathrm{nM}, 66 \mathrm{nM}, 88 \mathrm{nM}$, or $110 \mathrm{nM}$ ) after the switch into regular media and kept in the inhibitor until fixation. Contact-localized translation sites were determined by drawing a ROI from the cell contact until $5 \mu \mathrm{m}$ back. To determine 
the estimated number of translation sites and monomers $/ \mu \mathrm{m}^{3}$, we used the formula below:

$$
\begin{gathered}
\text { Estimated }_{\mathrm{TS}}=\text { Observed }_{\mathrm{TS}} \times 5^{\dagger}, \\
\frac{\text { Monomers }}{\mu \mathrm{m}^{3}}=\frac{\left(\text { Estimated }_{\mathrm{TS}} \times \text { total }_{\mathrm{NC}}\right) \times\left(\frac{180 \mathrm{~min}}{\text { rate }_{\mathrm{t}}}\right)}{660 \mu \mathrm{m}^{3}} .
\end{gathered}
$$

Estimated $_{\mathrm{TS}}=$ estimated $\#$ of translation sites in $180 \mathrm{~min}$ of recovery, $\dagger=$ accounting for endogenous $\beta$-actin as determined by Western blot (Fig. 2D),

Observed $_{\mathrm{TS}}=$ number of translation sites counted at the contact, total $\mathrm{NC}_{\mathrm{N}}=$ number of nascent chains from a single mRNA (Rodriguez et al. 2006),

rate $_{\mathrm{t}}=$ rate of translation (Rodriguez et al. 2006), and

$660 \mu \mathrm{m}^{3}=$ observation volume in all experiments.

\section{Fluorescence in situ hybridization}

MDCK cells expressing full-length $\beta$-actin eGFP were hybridized with Cy5-labeled probes directed against the GFP coding sequence (Femino et al. 2003; Rodriguez et al. 2006). Three probes antisense to the GFP coding sequence were used: GFP-1, GGGTCTTGTA GTTGCCGTCGTCCTTGAAGAAGATGGTGCG; GFP-2, GGCTG TTGTAGTTGTACTCCAGCTTGTGCCCCAGGATGTT; and GFP -3, TCTTTGCTCAGGGCGGACTGGGTGCTCAGGTAGTGGTT GT. Images were acquired using a Zeiss wide field AxioObserver Z.1 microscope with a Cy5 filter set. The acquired images were processed using the $3 \mathrm{D}$ de-convolution algorithm.

\section{Image processing}

Images were taken on an inverted Zeiss microscope using Axiovision 4.8.2 software (Zeiss). Using a $63 \times$ oil immersion objective, 30 slices were taken for each slide with a step size of $0.24 \mu \mathrm{m}$. For the immunoflourescence experiments, binning was set to $2 \times 2$, and the digital gain was 2 using a Cool Snap $\mathrm{HQ}^{2}$ (Photometrics). Imaging of the translation sites was done using a QuantEM:512SC (Photometrics) with a gain of 300-600. De-convolution was iterative for all images, and arrangements were done using Adobe Photoshop CS5 and ImageJ (NIH).

\section{Asymmetry coefficient analysis}

De-convolved Z-stacks were imported into Volocity 6.0 to calculate the Pearson's correlation values for cells (colocalization of adheren junction complex proteins and actin) at the various time-points of the calcium switch. Free-hand drawn regions on the junction or the cytoplasm of the cells were used to collect the Pearson's correlation values for each region. The asymmetry coefficient (AC) is the ratio of junction to cytoplasm values that were averaged (see Supplemental Fig. 1). An AC value $>1$ indicates that the colocalization of the two proteins is at the junction as opposed to the cytoplasm, while for $\mathrm{AC}$ values $<1$, colocalization is within the cytoplasm. Note: Pearson's correlation values for E-cadherin/actin colocalization were always positive and ranged from $0.1-1$. To calculate percent recovery, we divided the $\mathrm{AC}$ of the recovery by the $\mathrm{AC}$ of steady state, and multiplied it by 100 (see Supplemental Fig. 1). Data calculations and graphs were made using Microsoft Excel.

\section{Western blotting}

The total cell lysates for various time points during the $\mathrm{Ca}^{2+}$ switch assay were collected and probed for various AJ components by immunoblot. Briefly, the cells were harvested at the indicated time points, and lysed in lysis buffer with protease inhibitors (Pierce Biotechnology). The protein concentration was measured using the BiCinchoninic Acid (BCA) assay method as per the manufacturer's specifications (Fisher Scientific). The samples were denatured using sample loading buffer. Equal total protein for each sample $(7.5 \mu \mathrm{g})$ was loaded into each well of a $10 \%$ or $12 \%$ SDS-polyacrylamide gel, and proteins were separated using electrophoresis. Proteins were transferred onto a PVDF membrane, and the membrane was then blocked in 5\% skim milk. The membrane was incubated with mouse monoclonal primary antibodies E-cadherin (1:4000), $\beta$-catenin (1:4000), $\beta$-actin (1:4000), GFP (1:4000), or tubulin (1:3000) (BD Biosciences) for $2 \mathrm{~h}$ at room temperature or overnight at $4^{\circ} \mathrm{C}$. Primary antibody was followed by incubating with secondary antibody goat anti-mouse tagged to horseradish peroxidase (1:4000 or 1:5000) or goat anti-rabbit tagged to horseradish peroxidase (1:5000) for $2 \mathrm{~h}$ at room temperature (GE Healthcare). This was then followed by chemiluminescence detection (using Pierce Western blotting substrate as per the manufacturer's specifications) of the secondary, exposure on X-ray film, and quantification of the antigen probed using Image $\mathrm{J}(\mathrm{NIH})$ gel analysis software.

\section{Imaging RhoA activity in MDCK cells using a FRET-based biosensor}

Confluent monolayers of MDCK cells, transfected with pRBD-Ypet and CFP-RhoA, were either untreated or treated with control or antisense oligonucleotides and then subjected to $\mathrm{Ca}^{2+}$ switch experiments. The activation-dependent binding of CFP-RhoA to RBDYPet in live cells was visualized by imaging the sensitized emission of RBD-YPet (Kraynov et al. 2000). Images were captured using a LSM 510 NLO META with a Plan Apochromat 40× 1.0 NA oil objective (Carl Zeiss), using a 457-nm and 514-nm argon laser to excite the FRET pair. Processing of the FRET images was accomplished using the LSM FRET Tool macro (Carl Zeiss).

\section{SUPPLEMENTAL MATERIAL}

Supplemental material is available for this article.

\section{ACKNOWLEDGMENTS}

This work was supported by NSF \#0088668, NSF \#0538554, and NIH R25 60825-06 to N.G. and L.C., and the Rutgers Research Exchange Program to A.J.R.

Received October 29, 2013; accepted February 14, 2014.

\section{REFERENCES}

Angres B, Barth A, Nelson WJ. 1996. Mechanism for transition from initial to stable cell-cell adhesion: kinetic analysis of E-cadherinmediated adhesion using a quantitative adhesion assay. J Cell Biol 134: 549-557. 
Bailly M, Yan L, Whitesides GM, Condeelis JS, Segall JE. 1998. Regulation of protusion shape and adhesion to the substratum during chemotactic responses of mammalian carcinoma cells. Exp Cell Res 241: 285-299.

Ballestrem C, Wehrle_Haller B, Imhof BA. 1998. Actin dynamics in living mammalian cells. J Cell Sci 111: 1649-1658.

Bonder EM, Fishkind DJ, Mooseker MS. 1983. Direct measurement of critical concentrations and assembly rate constants at the two ends of an actin filament. Cell 34: 491-501.

Braga VM, Machesky LM, Hall A, Hotchin NA. 1997. The small GTPases Rho and Rac are required for the establishment of cadherin-dependent cell-cell contacts. J Cell Biol 137: 1421-1431.

Cao LG, Fishkind DJ, Wang YL. 1993. Localization and dynamics of nonfilamentous actin in cultured cells. J Cell Biol 123: 173-181.

Capaldo CT, Macara IG. 2007. Depletion of E-cadherin disrupts establishment but not maintenance of cell junctions in Madin-Darby canine kidney epithelial cells. Mol Biol Cell 18: 189-200.

Carramusa L, Ballestrem C, Zilberman Y, Bershadsky AD. 2007. Mammalian diaphanous-related formin Dial controls the organization of E-cadherin-mediated cell-cell junctions. J Cell Sci 120: 3870-3882.

Cavey M, Rauzi M, Lenne PF, Lecuit T. 2008. A two-tiered mechanism for stabilization and immobilization of E-cadherin. Nature 453: 751-756.

Chhabra ES, Higgs HN. 2007. The many faces of actin: matching assembly factors with cellular structures. Nat Cell Biol 9: 1110-1121.

Drees F, Pokutta S, Yamada S, Nelson WJ, Weis WI. 2005. a-catenin is a molecular switch that binds E-cadherin- $\beta$-catenin and regulates actin-filament assembly. Cell 123: 903-915.

Femino AM, Fogarty K, Lifshitz LM, Carrington W, Singer RH. 2003. Visualization of single molecules of mRNA in situ. Methods Enzymol 361: 245-304.

Gloushankova NA, Alieva NA, Krendel MF, Bonder EM, Feder HH, Vasiliev JM, Gelfand IM. 1997. Cell-cell contact changes the dynamics of lamellar activity in nontransformed epitheliocytes but not in their ras-transformed descendants. Proc Natl Acad Sci 94: 879-883.

Gu W, Pan F, Singer RH. 2009. Blocking $\beta$-catenin binding to the $Z B P 1$ promoter represses $Z B P 1$ expression, leading to increased proliferation and migration of metastatic breast-cancer cells. J Cell Sci 122: $1895-1905$.

Gu W, Katz Z, Wu B, Park HY, Li D, Lin S, Wells AL, Singer RH. 2012. Regulation of local expression of cell adhesion and motility-related mRNAs in breast cancer cells by IMP1/ZBP1. J Cell Sci 125: 81-91.

Harris TJ, Tepass U. 2010. Adherens junctions: from molecules to morphogenesis. Nat Rev Mol Cell Biol 11: 502-514.

Huttelmaier S, Zenklusen D, Lederer M, Dictenberg J, Lorenz M, Meng X, Bassell GJ, Condeelis J, Singer RH. 2005. Spatial regulation of $\beta$-actin translation by Src-dependent phosphorylation of ZBP1. Nature 438: 512-515.

Jaffe SH, Friedlander DR, Matsuzaki F, Crossin KL, Cunningham BA, Edelman GM. 1990. Differential effects of the cytoplasmic domains of cell adhesion molecules on cell aggregation and sorting-out. Proc Natl Acad Sci 87: 3589-3593.

Karakozova M, Kozak M, Wong CC, Bailey AO, Yates JR III, Mogilner A, Zebroski H, Kashina A. 2006. Arginylation of $\beta$-actin regulates actin cytoskeleton and cell motility. Science 313: 192-196.

Kislauskis EH, Zhu X, Singer RH. 1994. Sequences responsible for intracellular localization of $\beta$-actin messenger RNA also affect cell phenotype. J Cell Biol 127: 441-451.

Kobielak A, Pasolli HA, Fuchs E. 2004. Mammalian formin-1 participates in adherens junctions and polymerization of linear actin cables. Nat Cell Biol 6: 21-30.
Kovacs EM, Ali RG, McCormack AJ, Yap AS. 2002a. E-cadherin homophilic ligation directly signals through Rac and phosphatidylinositol 3-kinase to regulate adhesive contacts. J Biol Chem 277: 6708-6718.

Kovacs EM, Goodwin M, Ali RG, Paterson AD, Yap AS. 2002b. Cadherin-directed actin assembly: E-cadherin physically associates with the Arp $2 / 3$ complex to direct actin assembly in nascent adhesive contacts. Curr Biol 12: 379-382.

Kraynov VS, Chamberlain C, Bokoch GM, Schwartz MA, Slabaugh S, Hahn KM. 2000. Localized Rac activation dynamics visualized in living cells. Science 290: 333-337.

Lanni I, Ware BR. 1984. Detection and characterization of actin monomer, oligomers, and filaments in solution by measurement of fluorescence photobleaching recovery. Biophys J 46: 97-110.

Latham VM, Yu EH, Tullio AN, Adelstein RS, Singer RH. 2001. A Rhodependent signaling pathway operating through myosin localizes $\beta$-actin mRNA in fibroblasts. Curr Biol 11: 1010-1016.

McLachlan RW, Kraemer A, Helwani FM, Kovacs EM, Yap AS. 2007. E-cadherin adhesion activates c-Src signaling at cell-cell contacts. Mol Biol Cell 18: 3214-3223.

Nguyen AW, Daugherty PS. 2005. Evolutionary optimization of fluorescent proteins for intracellular FRET. Nat Biotechnol 23: 355-360.

Picard M, Petrie RJ, Antoine-Bertrand J, Saint-Cyr-Proulx E, Villemure JF, Lamarche-Vane N. 2009. Spatial and temporal activation of the small GTPases RhoA and Racl by the netrin-1 receptor UNC5a during neurite outgrowth. Cell Signal 21: 1961-1973.

Pollard TD, Mooseker MS. 1981. Direct measurement of actin polymerization rate constants by electron microscopy of actin filaments nucleated by isolated microvillus cores. J Cell Biol 88: 654-659.

Rodriguez AJ, Shenoy SM, Singer RH, Condeelis J. 2006. Visualization of mRNA translation in living cells. J Cell Biol 175: 67-76.

Rodriguez AJ, Czaplinski K, Condeelis JS, Singer RH. 2008. Mechanisms and cellular roles of local protein synthesis in mammalian cells. Curr Opin Cell Biol 20: 144-149.

Rosok O, Sioud M. 2004. Systematic identification of sense-antisense transcripts in mammalian cells. Nat Biotechnol 22: 104-108.

Saha S, Mundia MM, Zhang F, Demers RW, Korobova F, Svitkina T, Perieteanu AA, Dawson JF, Kashina A. 2010. Arginylation regulates intracellular actin polymer level by modulating actin properties and binding of capping and severing proteins. Mol Biol Cell 21: $1350-1361$.

Sahai E, Marshall CJ. 2002. ROCK and Dia have opposing effects on adherens junctions downstream of Rho. Nat Cell Biol 4: 408-415.

Scott JA, Shewan AM, den Elzen NR, Loureiro JJ, Gertler FB, Yap AS, 2006. Ena/VASP proteins can regulate distinct modes of actin organization at cadherin-adhesive contacts. Mol Biol Cell 17: 1085-1095.

Shestakova EA, Singer RH, Condeelis J. 2001. The physiological significance of $\beta$-actin mRNA localization in determining cell polarity and directional motility. Proc Natl Acad Sci 98: 7045-7050.

Vasioukhin V, Bauer C, Yin M, Fuchs E. 2000. Directed actin polymerization is the driving force for epithelial cell-cell adhesion. Cell 100: 209-219.

Volberg T, Geiger B, Kartenbeck J, Franke WW. 1986. Changes in membrane-microfilament interaction in intercellular adherens junctions upon removal of extracellular $\mathrm{Ca}^{2+}$ ions. J Cell Biol 102: 1832-1842.

Yamada S, Nelson WJ. 2007. Localized zones of Rho and Rac activities drive initiation and expansion of epithelial cell-cell adhesion. J Cell Biol 178: 517-527.

Yao J, Sasaki Y, Wen Z, Bassell GJ, Zheng JQ. 2006. An essential role for $\beta$-actin mRNA localization and translation in $\mathrm{Ca}^{2+}$-dependent growth cone guidance. Nat Neurosci 9: 1265-1273.

Zhang J, Betson M, Erasmus J, Zeikos K, Bailly M, Cramer LP, Braga VM. 2005. Actin at cell-cell junctions is composed of two dynamic and functional populations. J Cell Sci 118: 5549-5562. 

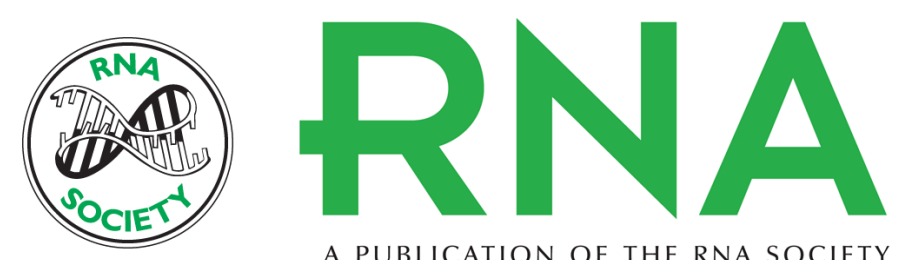

A PUBLICATION OF THE RNA SOCIETY

\section{The $\beta$-actin mRNA zipcode regulates epithelial adherens junction assembly but not maintenance}

Natasha Gutierrez, Itua Eromobor, Ryan J. Petrie, et al.

RNA 2014 20: 689-701 originally published online March 28, 2014

Access the most recent version at doi:10.1261/rna.043208.113

\section{Supplemental http://rnajournal.cshlp.org/content/suppl/2014/03/07/rna.043208.113.DC1 \\ Material}

References This article cites 42 articles, 23 of which can be accessed free at: http://rnajournal.cshlp.org/content/20/5/689.full.html\#ref-list-1

Creative This article is distributed exclusively by the RNA Society for the first 12 months after the Commons License full-issue publication date (see http://rnajournal.cshlp.org/site/misc/terms.xhtml). After 12 months, it is available under a Creative Commons License (Attribution-NonCommercial 4.0 International), as described at http://creativecommons.org/licenses/by-nc/4.0/. Email Alerting $\begin{aligned} & \text { Receive free email alerts when new articles cite this article - sign up in the box at the } \\ & \text { Service }\end{aligned}$ top right corner of the article or click here.

To subscribe to $R N A$ go to:

http://rnajournal.cshlp.org/subscriptions 